\title{
A NEURAL NETWORK CONTROLLER FOR THE DIRECT POWER CONTROL OF DOUBLY FED INDUCTION GENERATOR
}

\author{
Rodrigo Andreoli de Marchi, Paulo S. Dainez, Fernando J. Von Zuben and Edson Bim \\ State University of Campinas - UNICAMP \\ School of Electrical and Computer Engineering - P.O. Box 6101 - 13083-852 Campinas Brazil
}

ramarchi@dsce.fee.unicamp.br,psdainez@dsce.fee.unicamp.br, vonzuben@dca.fee.unicamp.brand bim@dsce.fee.unicamp.br

Abstract - In this paper a direct power control strategy for a doubly-fed induction generator by using an artificial neural network controller with the multilayer perceptron structure is presented. The control variables directand quadrature-axis rotor voltage signals are directly generated by proposed controller from both stator current and voltage that are measured by Hall sensors. The input variables of the control system are the rotor speed, the active and reactive power references and their respective errors. The proposed control strategy allows that the converter connected to the rotor terminals operate with constant switching frequency which simplifies the design of the AC harmonic filter and also prevents their power loss. To validate the proposed control strategy, digital simulation and experimental tests are performed for a $2.25 \mathrm{~kW}$ doubly-fed induction generator. A TMS320F2812 DSP is used to implement the neural network controller.

Keywords - Direct power control, Doubly-fed induction generator, Neural Network Controller, Multilayer perceptron, Constant switching frequency.

\section{LIST OF SYMBOLS}

$\begin{array}{ll}r_{s}, r_{r} & \text { stator, rotor resistances. } \\ L_{s}, L_{r}, L_{m} & \text { stator self, rotor self, mutual inductances. } \\ \sigma & \text { total leakage factor. } \\ \omega_{1}, \omega_{2}, \omega_{r} & \text { synchronous, slip, rotor angular frequency } \\ \theta_{1}, \theta_{2}, \theta_{r} & \text { stator flux, slip, rotor angles. } \\ P, Q & \text { active and reactive power. } \\ \bar{V}, \bar{I}, \bar{\psi} & \text { voltage, current, flux space vectors. } \\ v, i, \psi & \text { voltage, current, flux components. } \\ \bar{X}=x+j y & \begin{array}{l}\text { space vector expressed in the general } \\ \text { reference frame }\end{array} \\ s, r & \text { stator and rotor, respectively. } \\ \alpha, \beta & \text { direct- and quadrature-axis expressed in } \\ & \text { the stationary reference frame. } \\ \text { direct- and quadrature-axis expressed in } \\ \text { the synchronous reference frame. } \\ \text { direct- and quadrature-axis expressed in } \\ m, n & \text { the rotor reference frame. } \\ & \text { rotor coupling factor. }\end{array}$

\section{INTRODUCTION}

The use of the Doubly-Fed Induction Generator (DFIG) enables the control of its power flux from sources of mechanical energy that have variable speed, such as in wind

Artigo submetido em 17/01/2013. Primeira revisão em 19/04/2013, segunda revisão em $05 / 08 / 2013$. Aceito para publicação em $05 / 08 / 2013$ por recomendação do editor Henrique A. C. Braga. energy sources [1-3]. Another feature of the DFIG application is the control of the stator power flux by rotor terminals as shown in Figure 1, which makes it attractive for high power applications, because the rotor power is usually $1 / 4$ of the rated power of machine [4]. A DFIG application to make

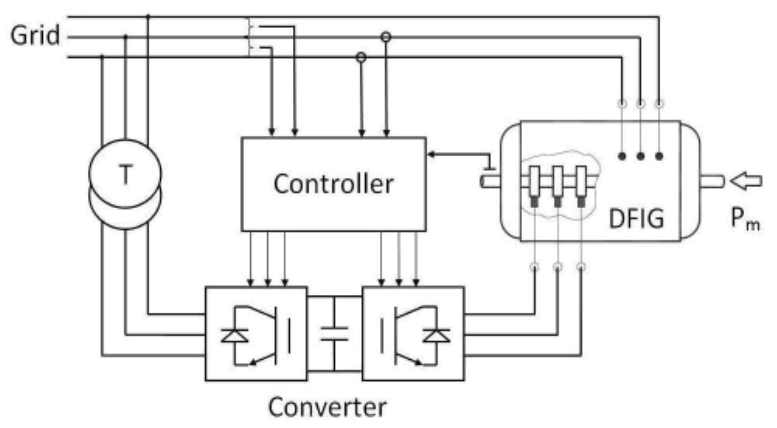

Fig. 1. Power flux in doubly fed induction generator.

better use of converters and improve the ability to control the total reactive power grid is proposed by [5]. PI controllers are also used for controlling the DFIG power flux to balanced voltages [6]- [7] and to grid voltage dip conditions in [8].

To obtain high dynamic performance in the reactive and active stator power control a direct power control (DPC) was developed [9], similar to the direct torque control (DTC) for the induction motor presented in [10]. The first works with DPC applied to the DFIG configuration used the hysteresis controller [11]. This entails a variable switching frequency, a high computational effort, and the necessity of stator side AC filters to eliminate broadband harmonics, consequently increasing in size and power loss. To overcome the disadvantage of working with variable switching frequency some strategies were developed for the DPC, as verified in [12], in which the acquisition of the rotor voltage components, the rotor speed measurement, the calculations of the active and reactive power and the stator flux estimation are all performed in a constant sample time, as presented in [13].

The DPC for a DFIG configuration with neuro-fuzzy inference system and a Takagi-Sugeno fuzzy logic controller of first order are proposed to determine the control variables $\mathrm{d}$-axis and q-axis rotor voltages in [13]. In [14] an artificial neural network (ANN) is used for estimating the wind speeds and from these data one obtains the ideal rotor speed that generates the maximum power. Aiming at increasing the efficiency of three-phase induction motor drives over the entire operation range, it is proposed by [15] the use of an ANN to predict the optimal rotor flux reference. To find the maximum power generation of a DFIG, a controller based on an ANN is also proposed by [16] and the digital simulation exhibited 
some advantages over a PI controller, such as lower picks in the controlled variable during the transitory and faster response. The inverse control logic applied to the stator power control of a DFIG proposed by [17] uses simultaneously a neural network and PI controllers to generate the control variables.

In this paper a direct power control strategy for a $2.25 \mathrm{~kW}$ DFIG is proposed and implemented using a controller based on an ANN with the multilayer perceptron (MLP) structure, which allows the control of the coupled and nonlinear system. The MLP controller generates direct- and quadrature-axis rotor voltage signals from the active and reactive power references, the active and reactive power errors and the rotor speed. The MLP was subject to an off-line training procedure and the set of samples for the supervised learning process was obtained from PI controllers. The single MLP controller replaces the PI controllers and the estimation block of the reference rotor currents reducing the number of blocks and variables to be implemented in the control loop, and this is its main advantage over the approaches mentioned earlier, including those already based on neural networks. Digital simulation and experimental tests for the DFIG operating at sub-synchronous speeds are presented to validate the proposed controller.

\section{FUNDAMENT OF DIRECT POWER CONTROL TO DOUBLY-FED INDUCTION GENERATOR}

\section{A. DFIG Model}

Adopting stator flux orientation, the DFIG model should be presented in the synchronous reference system. Supposing $r_{s} \cong 0$, the following set of equations holds [18]:

- Stator and rotor fluxes

$$
\begin{gathered}
\bar{\psi}_{s}=\psi_{d s}=\psi_{s}=L_{s} \bar{I}_{d q, s}+L_{m} \bar{I}_{d q, r} \\
\bar{\psi}_{d q, r}=\psi_{d r}+j \psi_{q r}=L_{r} \bar{I}_{d q, r}+L_{m} \bar{I}_{d q, s}
\end{gathered}
$$

- Stator and rotor voltages

$$
\begin{gathered}
\bar{V}_{d q, s}=V_{d, s}+j V_{q, s}=\frac{d \bar{\psi}_{s}}{d t}+j \omega_{1} \psi_{s} \\
\bar{V}_{d q, r}=V_{d, r}+j V_{q, r}=r_{r} \bar{I}_{d q, r}+\frac{d \bar{\psi}_{d q, r}}{d t}+j \omega_{2} \bar{\psi}_{d q, r}
\end{gathered}
$$

- Stator active and reactive powers

$$
\begin{aligned}
P_{s} & =\frac{3}{2} \mathcal{R} e\left(\bar{V}_{d q, s} \cdot \bar{I}_{d q, s}\right) \\
Q_{s} & =\frac{3}{2} \mathcal{I} m\left(\bar{V}_{d q, s} \cdot \bar{I}_{d q, s}\right)
\end{aligned}
$$

By combining Equations (1) and (2) one obtains the stator and rotor current expressions as a function of the flux:

$$
\begin{gathered}
\bar{I}_{d q, s}=\frac{\psi_{s}}{\sigma L_{s}}-\frac{k_{r} \bar{\psi}_{d q, r}}{\sigma L_{s}} \\
\bar{I}_{d q, r}=\frac{\bar{\psi}_{d q, r}}{\sigma L_{r}}-\frac{k_{r} \psi_{s}}{\sigma L_{s}}
\end{gathered}
$$

where,

$$
\sigma=1-\frac{L_{m}^{2}}{L_{s} L_{r}} \text { and } k_{r}=\frac{L_{m}}{L_{r}}
$$

Replacing Equations (3) and (7) into Equations (5) and (6), and after some algebraic manipulation, it follows that:

$$
\begin{gathered}
P_{s}=-k \omega_{1} \psi_{s} \psi_{q r} \\
Q_{s}=k \omega_{1} \psi_{s}\left(\frac{\psi_{s}}{k_{r}}-\psi_{d r}\right)
\end{gathered}
$$

where, $k=3 k_{r} / 2 \sigma L_{s}$.

With the infinite bus hypothesis, $\omega_{1}$ and $\psi_{s}$ are constants, and, consequently, the variation of the stator reactive and active powers $\left(\Delta P_{s}, \Delta Q_{s}\right)$ will be expressed as changes in direct- and quadrature-axis rotor flux given by:

$$
\begin{aligned}
& \Delta \psi_{q r}=-\frac{\Delta P_{s}}{k \omega_{1} \psi_{s}} \\
& \Delta \psi_{d r}=-\frac{\Delta Q_{s}}{k \omega_{1} \psi_{s}}
\end{aligned}
$$

\section{B. Direct power control (DPC)}

The stator active and reactive power are the controlled variables in the DPC, while the control variables are the direct- and quadrature-axis rotor voltages. Aiming at constant switching frequency, a constant sampling period $T_{s}$ is adopted, and if $r_{r} \bar{I}_{d q, r} \cong 0$, Equation (4) can be written as:

$$
\begin{aligned}
& V_{d r}=\frac{\Delta \psi_{d r}}{T_{s}}-\omega_{2} \psi_{q r} \\
& V_{q r}=\frac{\Delta \psi_{q r}}{T_{s}}+\omega_{2} \psi_{d r}
\end{aligned}
$$

By combining Equations (9), (10), (11) and (12), we obtain the following expressions for the direct- and quadrature-axis of the rotor voltage as a function of the stator flux:

$$
\begin{gathered}
V_{d r}=\frac{1}{k \omega_{1} \psi_{s}}\left[-\frac{\Delta Q_{s}}{T_{s}}+\omega_{2} P_{s}\right] \\
V_{q r}=\frac{1}{k \omega_{1} \psi_{s}}\left[-\frac{\Delta P_{s}}{T_{s}}-\omega_{2} Q_{s}\right]+\frac{\omega_{2}}{k_{r}} \psi_{s}
\end{gathered}
$$

Therefore, once the required $\Delta P_{s}, \Delta Q_{s}$ and $\omega_{2}$ is known, the rotor voltages can be determined.

\section{MLP CONTROLLER}

Neural networks are flexible mathematical devices to implement nonlinear controllers [19]. As the MLP with a single hidden layer is sufficient to approximate any continuous function inside a unit hypercube, it is convenient to normalize the training data [20]. The possibility of learning from data [21], the potential of preserving high levels of performance at distinct operating points [22], and the existence of statistical procedures aiming at promoting the maximization of the generalization capability $[23,24]$ are the main motivation for using neural networks controllers.

The number of neurons in the input and output layers is respectively defined by the number of inputs and outputs 
required by the application. There are no general guidelines for defining the best number of neuron in the hidden layer. The choice of a high number of hidden neurons might produce overfitting, thus reducing the generalization capability. The choice of a low number of neurons may impair the representation capability of the network, thus precluding the reduction of the training error [24]. What we have adopted here are twenty hidden neurons and what we considered enough to provide a proper degree of flexibility to the neural network and to avoid over training, $15 \%$ of the training data was kept apart as the validation dataset and the learning procedure stops when the neural network weights minimizes the error produced by the validation dataset.

\section{A. Training data}

The training data of the MLP are acquired from the based model control as presented in [25]. This control formulation has the advantage of decreasing the number of PI controllers from four to only two, as it is shown in Figure 2. The

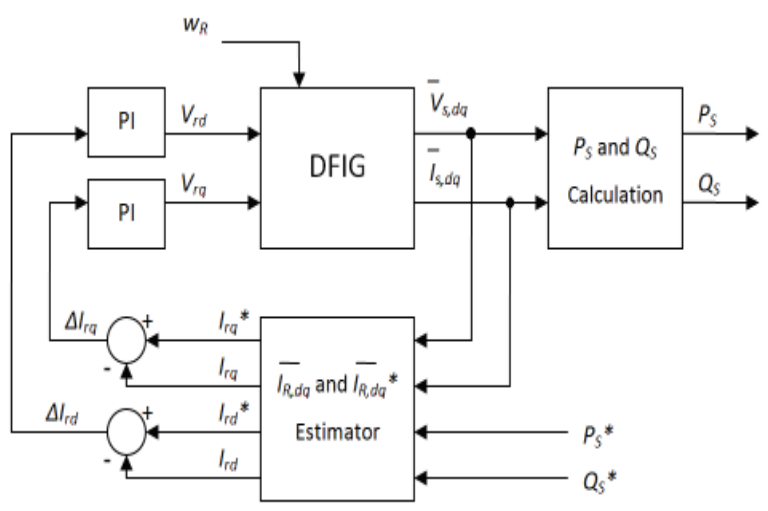

Fig. 2. Control diagram to generate the training dataset.

training dataset should contain samples from diverse operating conditions. This is a crucial requisite for the proper behavior of the obtained MLP controller.

The control system illustrated in Figure 2 is simulated for each of the speeds in the range of $\pm 15 \%$ of the synchronous speed $(160,175,188,201$ and $216 \mathrm{rad} / \mathrm{s})$ : for each speed the reference signals of the stator active and reactive power have the rectangular profile, as shown in Figure 3. The input data $P_{s}^{*}, Q_{s}^{*}, \Delta P_{s}, \Delta Q_{s}$ and $\omega_{r}$, and output data $V_{d r}$ and $V_{q r}$ utilized for training are selected and normalized around the transition of active and reactive powers, as highlighted in Figure 3 (data not selected are discarded) and the sampling frequency is $1 \mathrm{kHz}$. This selection avoids excess of redundant data, which could impair the training quality and increase the convergence time. The set of training data is normalized. It must also be emphasized that the gains of the PI controllers are set for each speed due to the nonlinearity that is inherent in induction machines and the PI controllers were adjusted by trial and error tuning method. This data acquisition policy guides to 2489 input-output samples to compose the training dataset. This training dataset is used as follows: $70 \%$ for adjusting the MLP weights, $15 \%$ for validation and $15 \%$ for test.

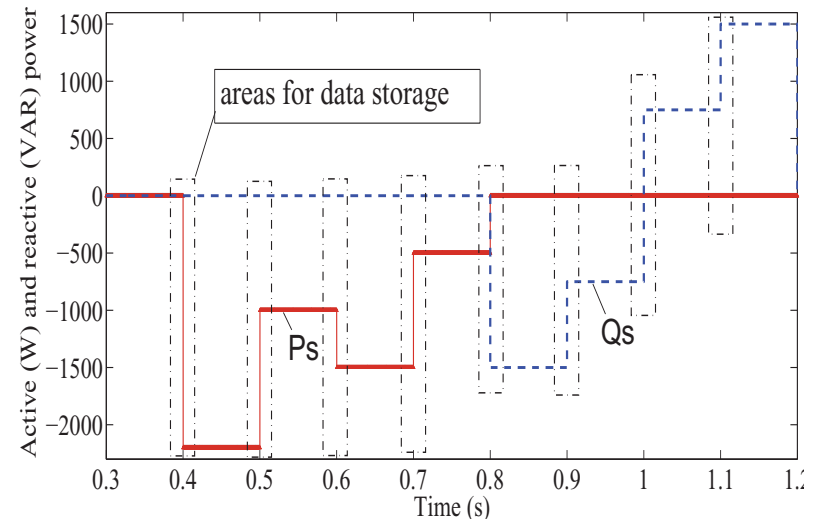

Fig. 3. Stator powers profiles to generate the training dataset.

\section{B. Training process}

The supervised learning (training process) is responsible for adjusting the weights of the MLP by means of the following iterative rule:

$$
W[t+1]=W[t]+\Delta W[t]
$$

where $W[t]$ is the vector composed by current values of the weights, $\Delta W[t]$ by incremental weight adjustment and $W[t+1]$ by the subsequent values of the weights. The incremental weight adjustment is performed so that the mean square error between the desired outputs and the obtained ones is minimized for the validation dataset, though only the training dataset is used to adjust the weights. In other words, the adjustment of the weights employs the training dataset, and the stopping condition is checked considering the validation dataset.

The supervised training process is generally performed offline and is characterized by a nonlinear optimization problem. As it is well-known in the context of nonlinear optimization, the iterative process may get stuck in local minima, depending on the initial value of the weights. To reduce the chance of converging to a poor local minimum, here we have adopted multiple restarting and we have also initialized the weights in a small interval around zero, e.g. $[-0.1,+0.1]$. We have adopted here a scaled conjugate gradient second-order method [26], used both for recurrent and nonrecurrent neural networks. This method is numerically stable, has a fast convergence and a low computational cost [27].

The maximum number of training epochs is limited to $10^{4}$. If the MSE associated with the validation dataset is still being reduced after $10^{4}$ epochs, then the algorithm will run for additional $10^{4}$ epochs. The computational demand can be considered low, with less than one minute to conclude $10^{4}$ epochs on conventional desktop.

\section{Proposed MLP controller}

The proposed MLP controller has five inputs $\left(Q_{s}^{*}, \Delta Q_{s}\right.$, $P_{s}^{*}, \Delta P_{s}$ and $\left.\omega_{r}\right)$, twenty neurons in the hidden layer and two neurons in the output layer $\left(V_{d r}\right.$ and $\left.V_{q r}\right)$, as it is illustrated in Figure 4. The MLP directly generates the rotor voltages $V_{d r}$ and $V_{q r}$ without PI controllers and without the estimation block for the reference rotor currents, as shown in Figure 5. 


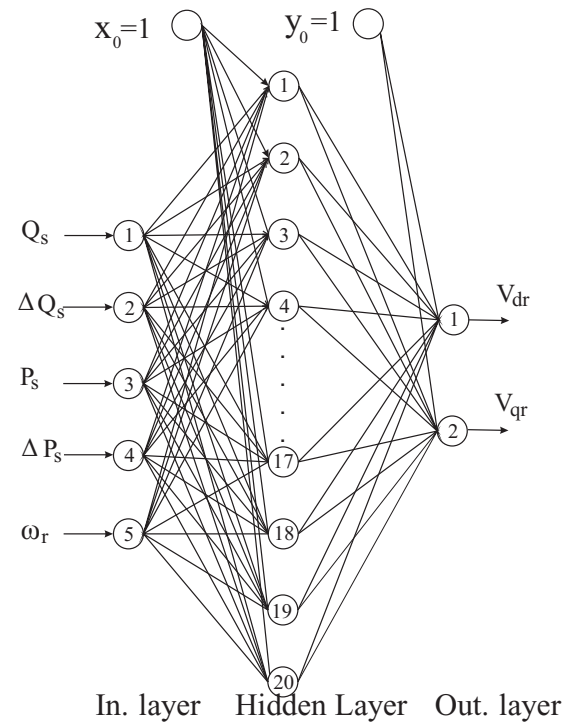

Fig. 4. Proposed MLP controller.

The weights associated with the synaptic connections between the input and the hidden layers are represented by matrix $W_{1}$, and the weights between the hidden and the output layers, by matrix $W_{2}$. The adopted activation function for the hidden layer neurons is the hyperbolic tangent and for the output layer neurons, the identity function. Hence, the output of the MLP is given by

$$
S_{r n}=\left[\tanh \left(X W_{1}^{t}\right)\right] W_{2}^{t}
$$

where $S_{r n}$ is the row vector with neural network outputs ( $V_{r d}$, $\left.V_{r q}\right), X$ is the row vector with all the input data $\left(P_{s}, Q_{s}, P_{s}^{*}\right.$, $Q_{s}^{*}$ and $\left.\omega_{R}\right)$ and $W_{1}^{t}, W_{2}^{t}$ are the transpose of matrices $W_{1}$ and $W_{2}$.

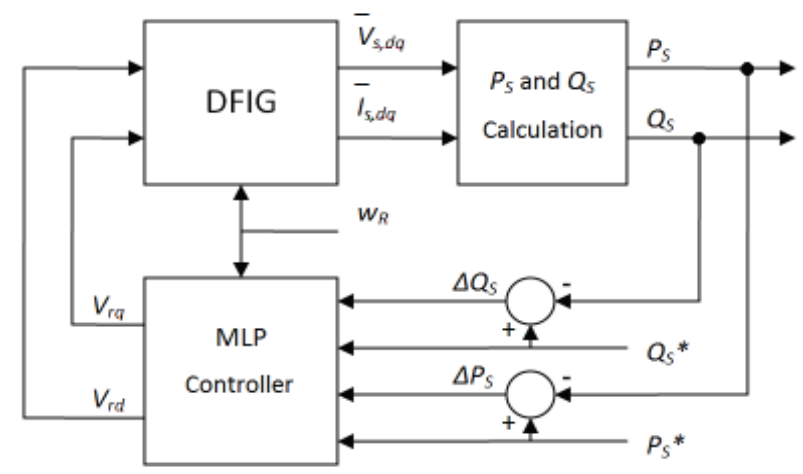

Fig. 5. Control Diagram with MLP Controller.

\section{SIMULATION AND EXPERIMENTAL RESULTS}

The simulation and experimental tests were performed with a $2.25 \mathrm{~kW}, 220 \mathrm{~V}, 60 \mathrm{~Hz}, 4$ poles. The control system block diagram is illustrated in Figure 6 and the description of each block is as follows:

- Transformations abc- $\alpha \beta$ and $\alpha \beta-d q$ block

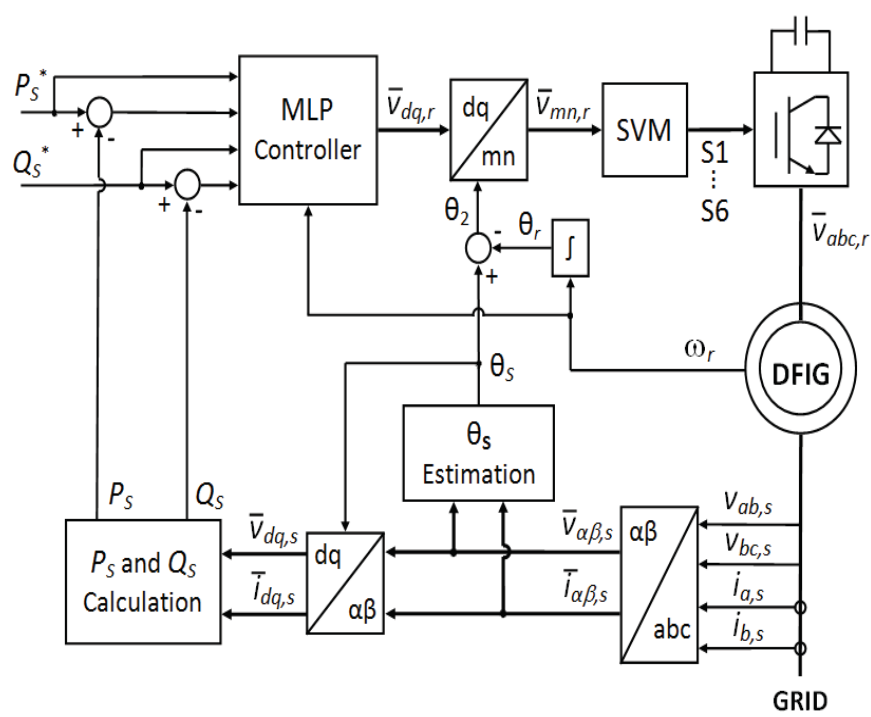

Fig. 6. System block diagram.

$$
\begin{gathered}
v_{\alpha}(t)=1 / 3\left[2 v_{a b s}+v_{b c s}\right] \\
v_{\beta}(t)=1 / \sqrt{3} v_{b c s} \\
i_{\alpha}(t)=i_{a s} \\
i_{\beta}(t)=1 / \sqrt{3}\left[i_{a s}+2 i_{b s}\right]
\end{gathered}
$$

- $\theta_{s}$ estimation

$$
\begin{gathered}
\bar{\psi}_{\alpha \beta s}=\int\left(\bar{V}_{\alpha \beta, s}-r_{s} \bar{I}_{\alpha \beta, s}\right) d t \\
\theta_{s}=\arctan \frac{\psi_{\beta s}}{\psi_{\alpha s}}
\end{gathered}
$$

- $P_{s}$ and $Q_{s}$ calculations are done by Equations (5) and (6)

- MLP controller

The MLP controller determines the control signals $V_{d r}$ and $V_{q r}$ from $P_{s}^{*}$ and $Q_{s}^{*}$ references, $\Delta P_{s}$ and $\Delta Q_{s}$ error, and $\omega_{r}$.

- $v_{m r}$ and $v_{n r}$ calculations

The control signals $V_{d r}$ and $V_{q r}$ are expressed in the rotor reference frame by

$$
\bar{V}_{m n, r}=v_{m r}+j v_{n r}=\bar{V}_{d q, r} e^{j\left(\theta_{s}-\theta_{r}\right)}
$$

\section{- Space vector modulation (SVM)}

To generate the pulse width modulation (PWM) switching patterns the Space vector modulation (SVM) is utilized. To maintain it in the linear zone of operation, the rotor voltages are limited by following functions:

$$
\begin{gathered}
\left|\bar{V}_{m n, r}(k)\right|=\sqrt{v_{m r}^{* 2}+v_{n r}^{* 2}} \\
\theta=\arctan \frac{v_{n r}}{v_{m r}} \\
\text { if }\left|\bar{V}_{m n, r}\right|>=V_{\text {max }, r} \text { then }\left|\bar{V}_{m n, r}\right|=V_{\text {max }, r}
\end{gathered}
$$

where $V_{\max , r}$ is the maximum voltage of the converter. 
The test bench is composed of a DSP Tms320F2812, interface circuits, an incremental encoder of 1500 pulses, a power converter of six IGBTs $(10 \mathrm{~kW})$, a personal computer and an oscilloscope. The DFIG rotor and stator terminals are connected to the power converter and to the infinite bus, respectively. A squirrel cage induction motor connected directly to the power grid was mechanically coupled to the DFIG to provide mechanical energy, i. e., the induction motor has no speed control. As hyperbolic tangent is not available in the mathematical library of the adopted DSP, the activation function of the hidden neurons in the MLP was implemented with an arc-tangent function [28]. In the DSP programming, two interruptions were implemented:

1) Interruption of $200 \mu \mathrm{s}$ - This time interval corresponds to the inverter switching period of $1 / 5 \mathrm{kHz}$ and the function performed are

- Calculation of the position and speed rotor from the encoder pulses.

- The MLP algorithm implementation to generate the output control signals $V_{d r}$ and $V_{q r}$.

- Generation of the command signals of the SVM.

2) Interruption of $50 \mu \mathrm{s}$ - In this period four updates of stator variables are permitted and the function performed are

- Voltages and current measurement of the stator line and the transformation of these variables to the stationary coordinate system.

- Estimation of the stator angular flux.

- Calculation of $P_{s}$ and $Q_{s}$.

\section{A. Simulation results for the variable speed operation}

The aim here is to verify the generalization capability of the trained MLP. So, all the operating range of the stator power and rotor speed were considered. The simulations were performed with reference values $\left(P_{s}^{*}, Q_{s}^{*}\right.$, and $\left.\omega_{r}^{*}\right)$ distinct from the ones considered in the training phase of the MLP, as shown in Figure 7.

In Figure 7(a) it is shown the imposed speed profile. Observe that the speed varies $15 \%$ around synchronous speed, which is the usual operating range for DFIGs . The stator active and reactive power profiles (reference and obtained) are shown in Figure 7(b).

In Figure 7(c), during the period where the power is null, it is observed that the stator currents are next to zero and respond immediately to the power variations, following the intended profiles.

In Figure $7(\mathrm{~d})$, it is observed that the amplitude and the phase sequence of the rotor currents change with respect to the stator power references and the subsynchronous/supersynchronous rotor speeds.

\section{B. Simulation and experimental results for constant speed operation}

The results presented in Figure 8 (simulation) and Figure 9 (experimental), with $w_{r}=180.0 \mathrm{rad} / \mathrm{s}$, are shown side by side for favoring the comparative analysis. Observe that $P_{s}$ and $Q_{s}$ are zero, before the first step in power reference.

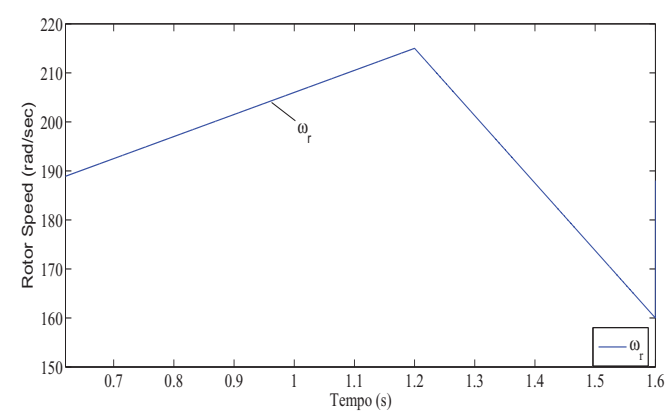

(a) Imposed Rotor speed.

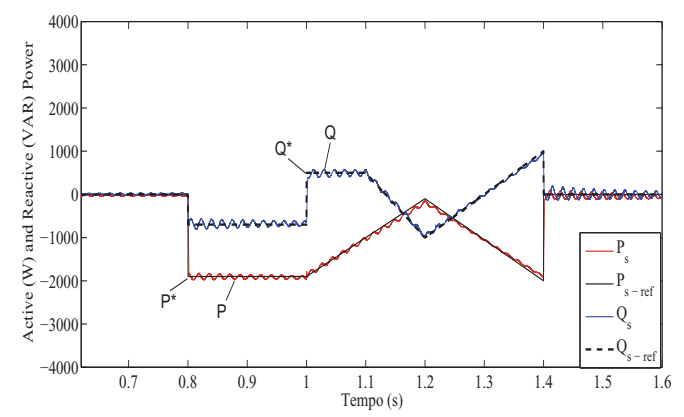

(b) Stator active and reactive power profiles.

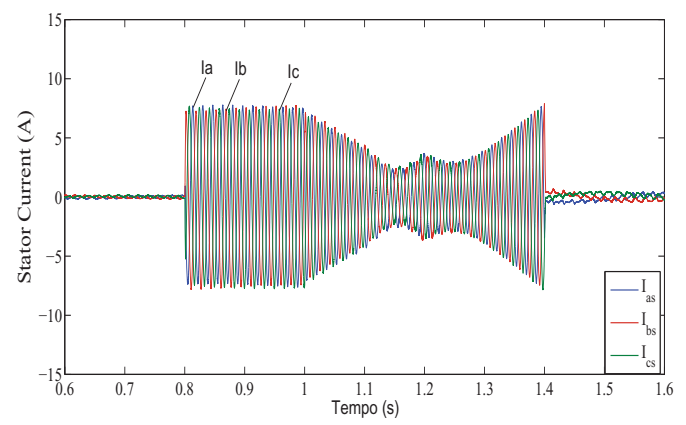

(c) Three-phase stator current waveforms.

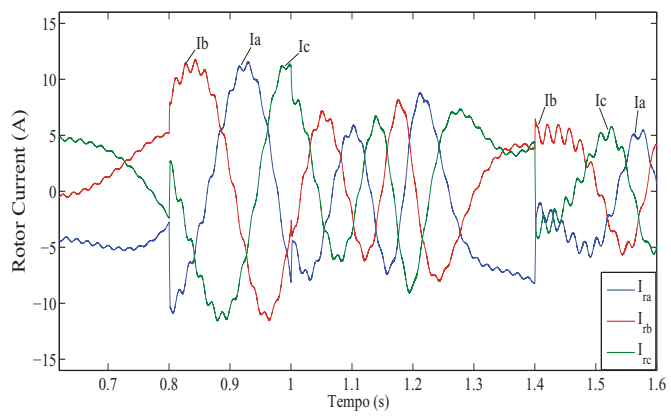

(d) Three-phase rotor current waveforms.

Fig. 7. Simulated results with variable speed. 


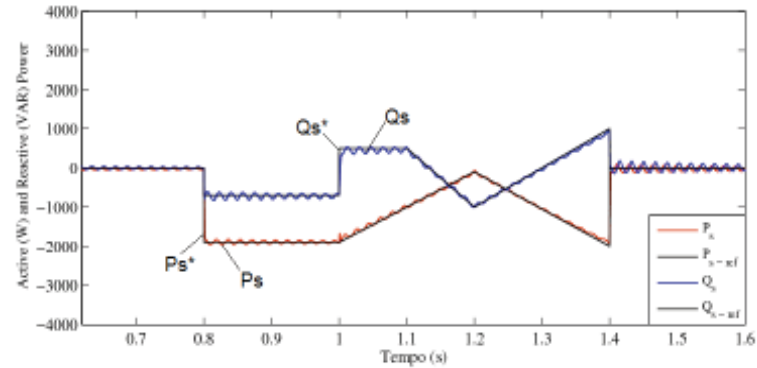

(a) Active and reactive power profiles.

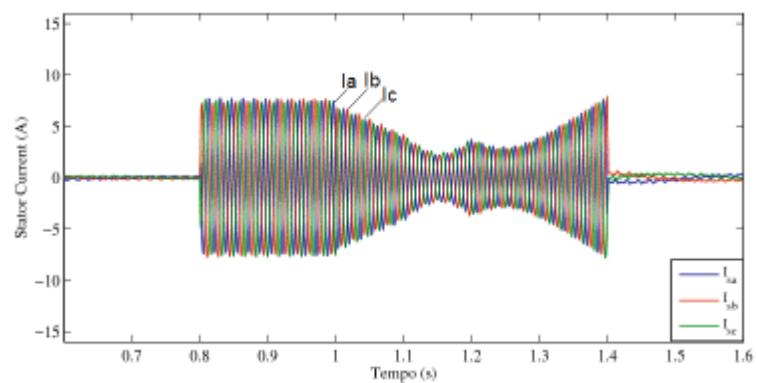

(b) Instantaneous values of the three-phase stator currents.

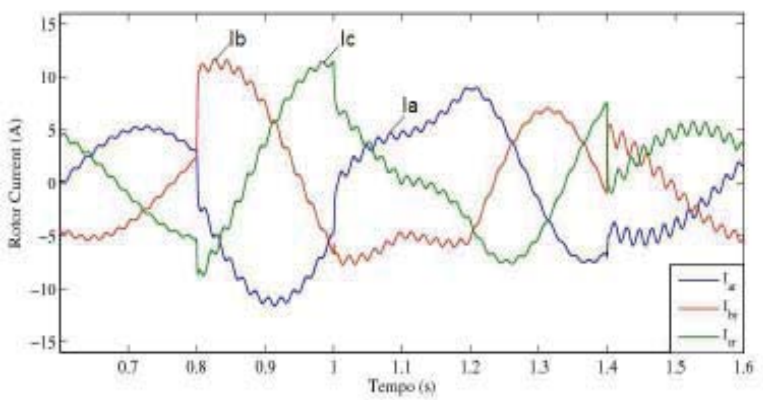

(c) Instantaneous values of the three-phase rotor currents.

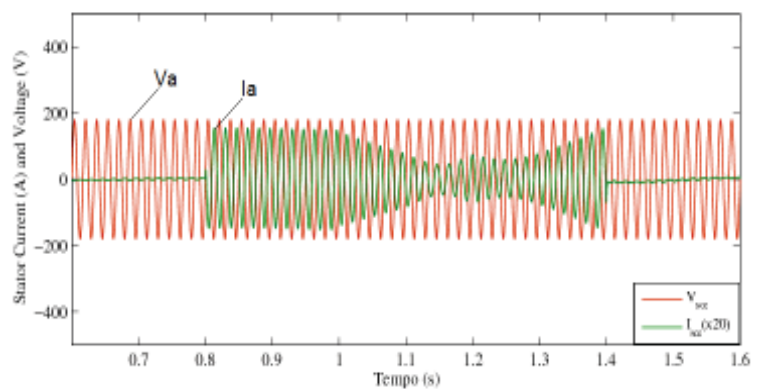

(d) Instantaneous current and voltage of one phase of the stator.

Fig. 8. Simulated results with sub-synchronous speed.

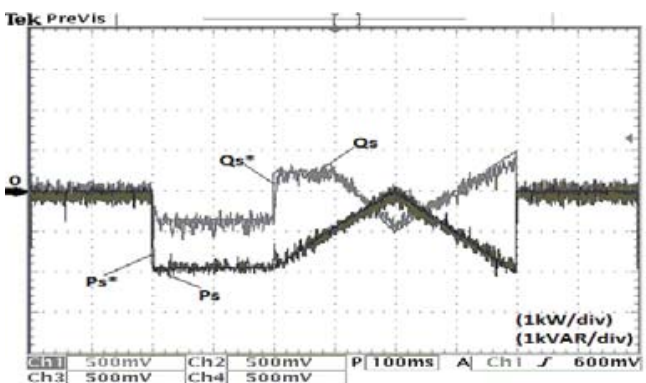

(a) Active $(1 \mathrm{~kW} /$ div $)$ and reactive $(1 \mathrm{kVAR} / \mathrm{div})$ power profiles.

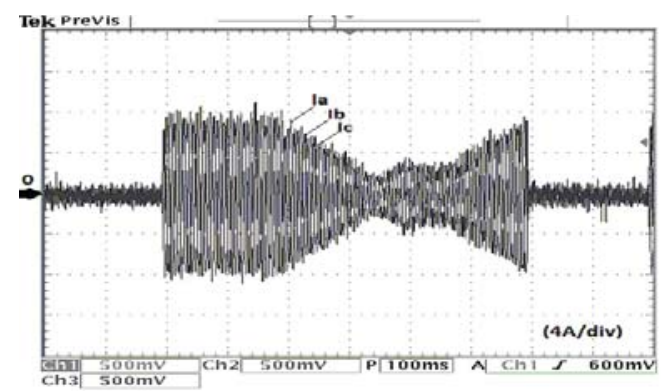

(b) Instantaneous values of the three-phase stator currents $(4 A / d i v)$.

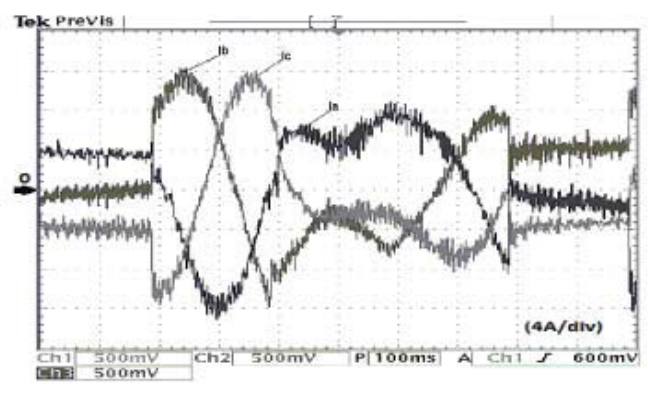

(c) Instantaneous values of the three-phase rotor currents $(4 A / d i v)$.

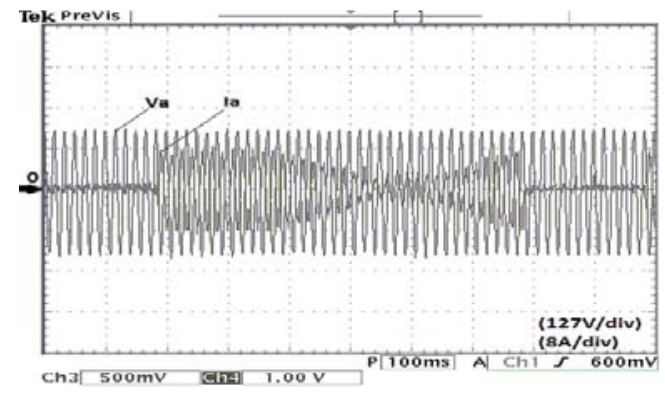

(d) Instantaneous current $(8 \mathrm{~A} / \mathrm{div})$ and voltage $(127 \mathrm{~V} /$ div $)$ of one phase of the stator.

Fig. 9. Experimental results with sub-synchronous speed. 


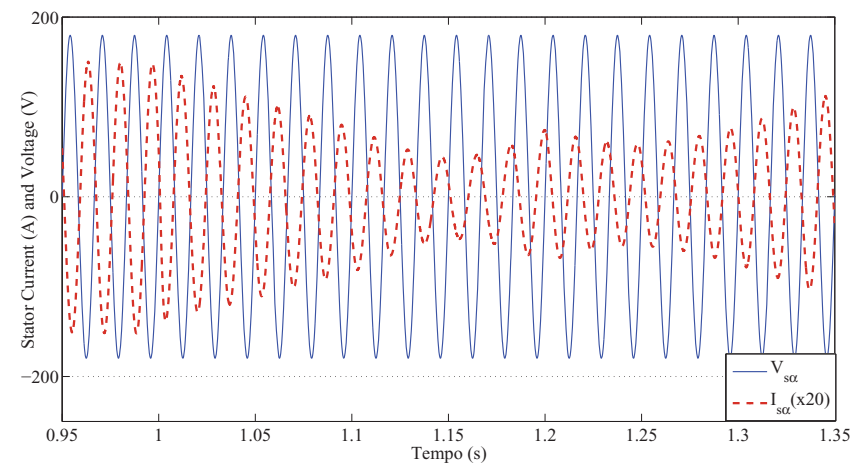

(a) The phase voltage and current of stator.

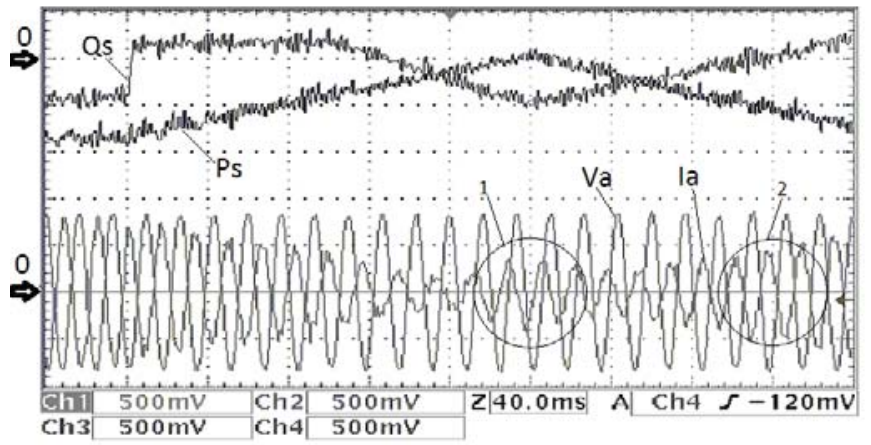

(b) Active $(1 k W / d i v)$ and reactive $(1 k V A R / d i v)$ power profiles in stator. The phase voltage $(127 \mathrm{~V} / \mathrm{div})$ and current $(8 A / d i v)$ of stator.

Fig. 10. Details of the variation in power factor: (a) simulation and (b) experimental.

During the period that the power is zero, the stator currents are next to zero and respond immediately to the required power, following the intended profiles, as shown in Figures 8(b) - 8(d) (simulation) and Figures 9(b) - 9(d) (experimental).

Furthermore, the phase angle of current regarding to the voltage, as shown in Figures 8(d) and 9(d), is $\pi$ radians, when the active power is not zero, and this is in accordance with the load convention. Regarding the reactive power, it is observed that the phase angle of current Is modified due to the changes in the power factor, i.e., leading (capacitive load) or lagging (inductive load) power factor. This effect is presented in details in Figure 10.

In Figures 8(c) -simulated results- and 9(c) -experimental results- it has been observed a small difference between the rotor currents waveforms because the digital simulation was performed with a constant speed of $180.0 \mathrm{rad} / \mathrm{s}$ and in the experimental test, the generator is driven by squirrel cage motor without speed control.

Thus, it is possible to conclude that the dynamic- and steady-state responses of the experimental results (Figure 9) are very close to the reference values and consistent with the simulation.

\section{CONCLUSION}

This paper has shown the experimental application of a direct power control of a doubly-fed induction generator under oriented stator flux using a controller based on an ANN. All the PI controllers and rotor current estimation block, that generated the set of samples for training process were replaced with success by a single MLP controller with twenty hidden neurons. The results have shown that the DPC approach combined with the MLP controller maintain the features of the DPC and adds the inherent characteristic of an ANN controller, more specifically the capability of controlling the coupled and nonlinear system and to generalize the performance to the whole range of operation considered in the training data. Furthermore, the execution and application of this controller are conceptually and computational simple, besides presenting a good performance. The experimental results have shown the effectiveness of the controller when attending changes in reactive and active power under subsynchronous speed, being these results consistent with those obtained by simulations.

\section{APPENDIX}

TABLE I

Nominal values of the $2.25 \mathrm{~kW}$ DFIG

\begin{tabular}{cc}
\hline \hline Parameters & Value \\
\hline \hline Power, Voltage & $2.25 \mathrm{~kW}, 220 \mathrm{~V}$ \\
\hline Frequency, Poles & $60 \mathrm{~Hz}, 4$ \\
\hline$r_{s}, r_{r}$ & $1.2,1.24[\Omega]$ \\
\hline$L_{s}, L_{r}, L_{m}$ & $98.14,98.14,91.96[\mathrm{mH}]$ \\
\hline
\end{tabular}

\section{ACKNOWLEDGEMENT}

The authors would like to thank Capes and CNPq for the financial support.

\section{REFERENCES}

[1] B. H. Chowdhury and S. Chellapilla. Double-fed induction generator control for variable speed wind power generator. Electric Power System Research, 76:786-800, 2006.

[2] I. Cardici and M. Ermis. Double-output induction generator operating at subsynchronous and supersynchronous speeds: steady-state performance optimization and wind-energy recovery. IEE Proceedings B, 139:429-442, 1992.

[3] R. Datta and V. T. Rangathan. Variable-speed wind power generation using doubly fed wound rotor induction machine - a comparison with alternative schemes. IEEE Trans. Energy Conversion, 17:414-421, 2002.

[4] F. Blaabjerg and F. Iov. Wind power - a power sourcer now enabled by power electronics. In Brazilian Power Electronics Conference, pages 1-16, 2007.

[5] R. G. de Oliveira, J. L. da Silva, and S. R. Silva. Desenvolvimento de uma nova estratégia de controle de potência reativa em gerador de inducão de dupla alimentacão para turbinas eólicas. Eletrônica de Potência, 13(4):207-284, Nov. 2008. 
[6] S. T. Jou, S. B. Lee, Y. B. Park, and K. B. Lee. Direct power control of a dfig in wind turbines to improve dynamics responses. Journal of Power Electronics, 9(4):781-790, Sept. 2009

[7] A. Petersson, L. Harnefors, and T. Thiringer. Evaluation of current control methods for wind turbines using doubly-fed induction machines. IEEE Trans. Power Electron., 20:2270-2281, 2005.

[8] F. K. de A. Lima, E. H. Watanabe, P. Rodriguez, and A. Luna. Controle de gerador de inducão duplamente alimentado diante de afundamentos de tensão. Eletrônica de Potência, 3(14):189-199, 2009.

[9] R. Datta and V.T. Ranganathan. Direct power control of grid-connected wound rotor induction machine without rotor position sensors. IEEE Trans. Power Electron., 16:1058-1066, 2001.

[10] I. Takahashi and T. Noguchi. A new quick-response and high-efficiency control strategy of an induction motor. IEEE Transactions Industry Applications, 22:820-827, 1986.

[11] Lie Xu and P. Cartwright. Direct active and reactive power control of dfig for wind energy generation. IEEE Trans. Energy Conversion, 21(3):750-758, Sept. 2006.

[12] D. Zhi and L. Xu. Direct power control of dfig with constant switching frequency and improved transient performance. IEEE Trans. Energy Conversion, 22:110118, 2007.

[13] R. V. Jacomini and E. Bim. Direct power control of a doubly fed induction generator by using a neuro-fuzzy controller. Eletrônica de Potência, 16(4):330-338, Nov. 2011.

[14] O. Barambones, J. M. G. Durana, and E. Kremers. A neural network based wind speed estimator for a wind turbine control. 15th IEEE Mediterranean Eletrotechnical Conference, pages 1383-1388, 2010.

[15] A. F. Santos, F. A. S. Neves, R. R. B. Aquino, and M. C. Cavalcanti. Application of artificial neural network in the efficient control of three-phase induction motor. Eletrônica de Potência, 15(2):87-96, May 2010.

[16] O. Soares, H. Gonçalves, A. Martins, and A. Carvalho. Nonlinear control of the doubly-fed induction generator in wind power systems. Renewable and Energy, 35:1662-1670, 2010.

[17] L. Li and K. Wang. Doubly-fed generation system based on neural network inverse control. Second International Symposium on Knowledge Acquisition and Modeling, pages 147-150, 2009.

[18] Edson Bim. "Máquinas Elétricas e Acionamento". Elsevier Publications, 2012.

[19] W. T. Miller, R. S. Sutton, and P. J. Werbos. "Neural Networks for Control". Bradford Book, 1995.

[20] K. Hornik, M. Stinchkombe, and H. White. Multilayer feedforward networks are universal approximators. Neural Networks, 2(5):359-366, Febr. 1989.

[21] V. Cherkassky and F. Mulier. "Learning from Data: Concepts, Theory, and Methods". Wiley, 2007.

[22] L. A. C. Meleiro, F. J. Von Zuben, and R. Maciel Filho. Constructive learning neural network applied to identification and control of a fuel-ethanol fermentation process. Engineering Applications of Artificial Intelligence, 22:201-215, 2009.

[23] T. M. Mitchell. "Machine Learning". McGraw-Hill, 1997.

[24] S. Haykin. "Neural Networks and Learning Machines". Wiley, 2008.

[25] R. V. Jacomini, A. França, and E. Bim. Simulation and experimental studies on double-fed induction generator power control operating at subsynchronous operation speed. Power Electronics and Drive Systems. International Conference on, pages 1421-1424, 2009.

[26] E. P. dos Santos and F. J. Von Zuben. Improved secondorder training algorithms for globally and partially recurrent neural networks. Proceedings of the IEEE International Joint Conference on Neural Networks, 3:1501-1506, 1999.

[27] M. F. Moller. A scaled conjugate gradient algorithm for fast supervised learning. Neural Networks, 6:525-533, 1993.

[28] K. Najarian. On learning of sigmoid neural networks. Complexity, 6(4):39-45, Jun. 2001.

\section{BIOGRAPHIES}

Rodrigo Andreoli de Marchi received the B.S. degree (2008) in electrical engineering from Methodist University of Piracicaba, Brazil, the M.S. degree (2011) from State University of Campinas, Brazil and currently he is working toward the Ph.D. degree at the State University of Campinas. His current research interests include AC drives and neural networks control applied to squirrel cage and doubly fed induction machines.

Paulo Sergio Dainez received the B.Sc. degree in electrical engineering from Federal University of Santa Catarina, Brazil, in 1994, the M.Sc. degree in electrical engineering from State University of Santa Catarina, Brazil, in 2010. From 1994 to 2011, he was an Electrical Engineer in the Whirlpool Compressor Unit - Brazil. Since 2011, he is working toward the Ph.D. degree in electrical engineering from State University of Campinas, Brazil. His current research interest include control and simulation of electrical machines, Multiphase motor and AC drives.

Fernando J. Von Zuben received his Dr.E.E. degree from the University of Campinas (Unicamp), Campinas, SP, Brazil, in 1996. He is currently the header of the Laboratory of Bioinformatics and Bioinspired Computing (LBiC), and an Associate Professor at the Department of Computer Engineering and Industrial Automation, School of Electrical and Computer Engineering, University of Campinas (Unicamp). The main topics of his research are computational intelligence, bioinspired computing, multivariate data analysis, and machine learning. He coordinates open-ended research projects in these topics, tackling real-world problems in the areas of information technology, decision-making, pattern recognition, and discrete and continuous optimization. He has concluded the supervision of more than 40 graduate students, and has published more than 60 full research papers and more than 200 conference papers. Fernando J. Von 
Zuben is IEEE Senior Member and also a member of the Evolutionary Computation Technical Committee of the IEEE Computational Intelligence Society.

Edson Bim received the B.S., M.S., and Ph.D. degrees, in electrical engineering from the State University of Campinas (UNICAMP), Campinas, São Paulo, Brazil, in 1976, 1981, and 1993, respectively. Since 1977 he has been Professor with the Faculty of Electrical and Computer Engineering, University of Campinas (Unicamp) and he is currently an Associate Professor. He has written one book (Portuguese language, 2nd Edition), secured one Brazil patent and published technical papers. Much of his current research focuses on predictive adaptive and neural networks control applied to three-phase and multiphase induction machines. 